Revista lus et Praxis, Año 25, No 1, 2019, pp. 415 - 438

ISSN 0717 - 2877

Universidad de Talca - Facultad de Ciencias Jurídicas y Sociales

Mecanismos alternativos de solución de conflictos en materia penal en Chile.

Una propuesta de lege ferenda

Raúl Carnevali R.

Trabajo recibido el 9 de abril y aprobado el 19 de diciembre de 2018

\title{
Mecanismos alternativos de solución de conflictos en materia penal en Chile. Una propuesta de lege ferenda*
} Alternative Dispute Resolution in criminal matters in Chile. A PROPOSAL DE LEGE FERENDA

Raúl Carnevall R.**

\section{RESUMEN}

La introducción de mecanismos alternativos de solución de conflictos en la justicia penal se viene discutiendo desde hace largos años. Entre otras razones, por la desconfianza que actualmente genera el sistema retributivo y por la escasa atención que se presta a la víctima, dado que la relación se centra, esencialmente, en el Estado y el autor del delito. El trabajo pretende examinar por qué se hace necesario otorgar una mayor relevancia a la justicia restaurativa, dirigiéndose a la experiencia comparada, en especial la mexicana y colombiana. A continuación, se ofrece una propuesta de lege ferenda, determinando la oportunidad procesal para incorporar estos mecanismos. Si bien no se intenta reemplazar la justicia penal tradicional, sí pueden servir de complemento, pues también pueden alcanzar propósitos preventivos.

\section{ABSTRACT}

The introduction of alternative procedures to resolve conflicts in criminal justice has been discussed for many years. Amongst other reasons, the suspicion the compensation scheme currently creates and the limited support given to the victim, given that the relationship is, essentially, focused on the State and the perpetrator of the crime. The study aims to examine why it is necessary to give greater relevance to restorative justice, addressing comparative examples, in particular Mexican and Colombian. Furthermore, a de lege ferenda proposal is offered, determining the legal opportunity to incorporate these procedures. Although there is no attempt to replace traditional criminal justice, they can complement one another, since they can also achieve preventive purposes.

\section{PALABRAs CLAVE}

Justicia restaurativa, víctima, delito, reparación, prevención

KEY WORDS

Restorative justice, victim, crime, reparation, prevention

\footnotetext{
* Este trabajo forma parte del Proyecto Anillo titulado "Los Métodos Alternativos de Solución de Conflictos como herramientas de modernización de la justicia. Construcción dogmática a partir de un análisis multidisciplinar", financiado por Conicyt Chile (SOC 1406).

** Doctor en Derecho. Profesor titular de Derecho penal, Universidad de Talca (Chile). Decano de la Facultad de Ciencias Jurídicas y Sociales de la misma universidad. E-mail: rcarnevali@utalca.cl.
} 


\section{Aproximación al tema}

Desde hace ya un tiempo viene discutiéndose si es posible resolver algunos conflictos penales a través de mecanismos propios de la justicia restaurativa. Lo anterior por las ventajas que representaría su implementación, sobre todo desde la perspectiva de la víctima y su reparación, así como por el impacto que tendría respecto del autor, pues al no imponerse en propiedad una pena, puede haber respecto de aquél un mayor efecto preventivo especial. En efecto, como ya se afirmó en otro trabajo', instrumentos como la mediación penal manifiestan mayor preocupación por la víctima, entendida ésta como el otro protagonista del delito, al buscar especialmente su satisfacción -no solo de carácter pecuniario- e inclusión ${ }^{2}$. Y es que la imposición de un castigo muchas veces no alcanza a integrar a la víctima, al no otorgarle un sentido reparador $^{3}$. Por su parte, el desarrollo de los procesos propios de la justicia restaurativa al enfatizar en los encuentros, permite que autor y víctima se conozcan y con ello el alcance del hecho constitutivo de delito; es decir, por ejemplo, qué llevó al autor a la comisión del hecho. Incluso, respecto de este último, al relacionarse directamente con el sujeto pasivo a través de encuentros facilitará su comprensión de los efectos del delito -el drama causado a la víctima- reforzando su proceso de reinserción ${ }^{4}$.

Incluso se puede ahondar aún más en lo recién señalado, en cuanto a entender que en la medida en que sean los propios involucrados en el conflicto quienes lo solucionen, supone además una profundización de los componentes democráticos de una sociedad, ya que es la propia sociedad la que directamente administra justicia. Si bien estos instrumentos permiten descongestionar el sistema, su valor es más profundo, pues permiten materializar fines que son propios de las sociedades democráticas, como es procurar atender los conflictos y con ello alcanzar la paz social a través de

\footnotetext{
1 Carnevali (2017), pp. 122 y ss.; respecto de los orígenes, Cuadrado (2015), pp. 4 y ss.

${ }^{2}$ Lo indicado no quiere decir, ciertamente, que el sistema penal retributivo desatienda a la víctima. Pero es indudable que los actores principales son el Estado y el autor del delito, más que la víctima.

3 BARONA (2011), p. 158: "así, frente a la idea del castigo que arrastra tras de sí la clásica concepción de la justicia penal, lo que la restorative justice aporta es la idea de la persuasión. El objetivo de la pena es aumentar el temor por una pena mayor, mientras que el objetivo de la persuasión es aumentar el apoyo moral para alcanzar el respeto a la ley".

4 Bolívar (2014), pp. 26 y ss.; Cuadrado (2015), p. 17: "Una de las principales ventajas de la mediación frente a la justicia penal tradicional es su mayor eficacia en la rehabilitación del autor del hecho y, en consecuencia, en la reducción de los niveles de reincidencia. Es más, Shapland (et al.) afirma que uno de los motivos que estimulan a la víctima a formar parte de un proceso mediador es el convencimiento de que ello sirve a los efectos de ayudar a su infractor a no volver a delinquir".
} 
una participación activa y en condiciones de igualdad. Dicho, en otros términos, los procesos autocompositivos abren mayores espacios que permitan arribar a soluciones pacíficas y amigables, dotándolos de un componente de legitimidad difícil de soslayar ${ }^{5}$.

En esta línea, el Tribunal Constitucional de Colombia ha afirmado que los mecanismos alternativos de solución de conflictos no pueden ser interpretados solamente como una forma de descongestión del aparato de justicia sino también, y principalmente, como un instrumento de participación de la sociedad civil en los asuntos que los afectan. Asimismo, sigue la sentencia, estos mecanismos generan espacios de intervención de la comunidad en el desarrollo de la función jurisdiccional evitando así la conflictivización de la sociedad, fortaleciendo la legitimidad del aparato de justicia estatal en la medida en que éste puede dedicarse a resolver aquellos asuntos que son de verdadera trascendencia social ${ }^{6}$.

En este trabajo no me detendré a tratar las particularidades de la justicia retributiva y su distinción de la justicia retributiva, pues ya han sido examinadas anteriormente ${ }^{7}$, sino que pretendo exponer cómo debería recogerse dentro del sistema, esto es, cómo debería establecerse procedimentalmente. El propósito perseguido consiste en una propuesta legislativa, es decir,

${ }^{5}$ Cuadrado (2015), p. 2.

${ }^{6}$ Corte Constitucional de Colombia, rol № C-893-01, de 22 de agosto de 2001: "En criterio de algunos sociólogos del derecho estos procesos incrementan la democracia, al menos por cuatro razones: (i) porque acercan la justicia a los criterios populares de equidad. Por ejemplo, en muchos países los jueces de paz o muchos árbitros comunitarios deben decidir en equidad. Y en este contexto, equidad no significa que los jueces de paz deban recurrir a la concepción sobre el tema de un eminente filósofo, como Aristóteles o John Rawls, sino que quiere decir que las decisiones deben reflejar los criterios de justicia de las propias comunidades, con lo cual el derecho se hace más permeable a lo popular; (ii) porque son procesos participativos pues restituyen a las personas y a las comunidades la capacidad de resolver sus propias controversias, ya que en general las decisiones se fundan en el asentimiento de las partes involucradas; (iii) porque se fundan en el consenso, en la búsqueda de acuerdos, con lo cual incrementan la deliberación democrática, puesto que los ciudadanos deben aprender a defender los derechos propios pero reconociendo la legitimidad de los derechos ajenos. El espacio de la discusión pública pacífica debería entonces verse fortalecido. Y (iv), finalmente, porque, como lo han mostrado los Ilamados enfoques "transformadores" en el campo de la medicación[11], una solución conciliada de un conflicto tiende a fortalecer dos virtudes democráticas esenciales para un ciudadano: su autonomía, pues le enseña a manejar sus propios problemas, pero también la búsqueda del acuerdo, obliga a la persona a comprender al otro y expresar preocupación y consideración por sus intereses y valores, lo cual la vuelve un individuo más compasivo, solidario y con capacidad de reconocimiento del valor de las diferencias y del pluralismo. Esta es la opinión de Rodrigo Uprimny vertida en el documento "Jueces de Paz y Justicia Informal: una aproximación conceptual a sus potencialidades y limitaciones".

7 Carnevali (2017), pp. 123 y ss. 
una especie de modelo construido sobre la base de lo que existe en otras latitudes y que sea coherente con nuestro proceso penal. En efecto, existen legislaciones latinoamericanas que han incorporado sistemas propios de la justicia restaurativa para solucionar conflictos penales. Así sucede, entre otros ordenamientos, en México y Colombia, donde sus propias constituciones afirman la relevancia de estos instrumentos propios de la justicia restaurativa.

Sin perjuicio de lo que se afirmará más adelante, la Constitución de los Estados Unidos Mexicanos señala en el art. 17 lo siguiente: "Las leyes preverán mecanismos alternativos de solución de controversias. En la materia penal regularán su aplicación, asegurarán la reparación del daño y establecerán los casos en los que se requerirá supervisión judicial". Este artículo fue introducido en la importante reforma a la Constitución en materia de justicia penal y seguridad pública de 18 de junio de $2008^{8}$. Es así, que a partir de entonces comienzan a incorporarse cambios legislativos que culminan con la Ley nacional sobre Mecanismos Alternativos de solución de controversias en materia penal de fecha 29 de diciembre de $2014^{9}$.

En el caso colombiano, su Constitución también establece un marco normativo que permite sustentar la instauración de mecanismos propios de la justicia restaurativa. Es así, que el artículo 116 indica: "Los particulares pueden ser investidos transitoriamente de la función de administrar justicia en la condición de jurados en las causas criminales, conciliadores o en la de árbitros habilitados por las partes para proferir fallos en derecho o en equidad, en los términos que determine la ley". Luego, en las disposiciones relativas a la Fiscalía General de la Nación se afirma en el artículo 250.7: "Velar por la protección de las víctimas, los jurados, los testigos y demás intervinientes en el

\footnotetext{
${ }^{8}$ Las razones que se argumentaron fueron, en buena parte, de orden económico, al permitir una mayor descongestión en el trabajo del Ministerio Público, tal como se señala en SubDirección de ArCHivo y DOCUMENTACIÓn (2008): "Todas estas medidas se justifican sobre la base de que, en nuestro país, hoy en día, empleamos la gran mayoría de los recursos públicos en persecuciones penales extensas, costosas, y de muy cuestionable interés para la seguridad pública. La gran mayoría de las personas que componen la población penitenciaria cometió hurtos menores, no violentos; sin embargo, en procesar esta clase de delitos se gastaron miles de pesos y su duración-que normalmente consume alrededor de 100 días- contrasta con la celeridad con que este tipo de asuntos se despachan en países como, por ejemplo, Chile, que resuelve este tipo de casos en la misma audiencia de control de la detención, a escasas 24 horas del arresto, en un encuentro que concluye con una sentencia al cabo de 15 minutos. El Ministerio Público podrá ahorrar dinero público al evitar un gran número de persecuciones penales innecesarias, sea porque hay débiles posibilidades de un litigio exitoso, o porque se trate de asuntos de escaso interés para la seguridad pública; en resumen, estos ingredientes crean múltiples vías para descongestionar al Ministerio Público y emplear los recursos racionalmente".

${ }^{9}$ Ley Nacional de Mecanismos Alternativos de Solución de Controversias en Materia Penal, de diciembre de 2014.
} 
proceso penal, la ley fijará los términos en que podrán intervenir las víctimas en el proceso penal y los mecanismos de justicia restaurativa". Precisamente, estos mecanismos a los que alude la norma citada se precisan en la Ley $\mathrm{N}^{\circ} 906$ de 2004 por la cual se expide el Código de procedimiento penal. Pues bien, en los artículos 518 y siguientes se dispone de todo un libro -el VI-sobre justicia restaurativa. Allí se define qué debe entenderse por tal. Es así, que el artículo 518 señala que: "Se entenderá por programa de justicia restaurativa todo proceso en el que la víctima y el imputado, acusado o sentenciado participan conjuntamente de forma activa en la resolución de cuestiones derivadas del delito en busca de un resultado restaurativo, con o sin la participación de un facilitador. Se entiende por resultado restaurativo, el acuerdo encaminado a atender las necesidades y responsabilidades individuales y colectivas de las partes y a lograr la reintegración de la víctima y del infractor en la comunidad en busca de la reparación, la restitución y el servicio a la comunidad". Luego en el artículo 522 se precisa que los mecanismos de la justicia restaurativa son la conciliación preprocesal, la conciliación en el incidente de reparación integral y la mediación.

En lo que respecta a la Argentina, en el nuevo Código procesal penal, producto de la reforma de 2014, se dispone en el artículo 22 que debe procurarse resolver los conflictos prefiriendo aquellas soluciones que faciliten una mayor armonía entre los protagonistas del delito. En este contexto, se regula el mecanismo de la conciliación en el artículo 34, el que de forma algo escueta indica que el imputado y la víctima podrán realizar acuerdos conciliatorios tratándose de delitos con contenido patrimonial cometidos sin grave violencia sobre las personas o en los delitos culposos si no existieran lesiones gravísimas o resultado de muerte. El acuerdo se debe presentar ante el juez para su homologación, si correspondiere, en audiencia con la presencia de todas las partes.

Si bien en Chile hay algunos proyectos, sobre todo en materia juvenil, en que se pretende avanzar en la instauración de instrumentos restaurativos, es muy poco lo que se puede decir aún ${ }^{10}$. En efecto, en el Código procesal penal solo pueden citarse la suspensión condicional de procedimiento y los acuerdos reparatorios, pero que en rigor no son propiamente mecanismos alternativos de solución de conflictos ${ }^{11}$. En el caso de la suspensión el rol de

10 Comisión de Constitución, Legislación, Justicia y Reglamento, Senado (2017).

11 Para GonZÁlez (2014), pp. 40-45, la suspensión condicional del procedimiento es lo más cercano a la conciliación. En cambio, en los acuerdos reparatorios, la mediación es el proceso más adecuado. Ver también BLANCO et al. (2004), pp. 77-81. 
la víctima es limitado -la que solo puede ser escuchada- y se autoriza en la medida que el imputado preste su consentimiento, imponiéndosele determinadas cargas de carácter sancionatorio -artículos 237 y siguientes-. Aun cuando los acuerdos reparatorios comparten ciertas particularidades con un programa de justicia restaurativa, pues se requiere acuerdo entre la víctima y el imputado, donde se procura la reparación de aquélla, tampoco puede afirmarse que es un mecanismo alternativo de solución de conflictos. Y es que no interviene nadie en calidad de mediador o facilitador que permita cumplir con los fines que se buscan. Como son, por ejemplo, el encuentro, a través del cual los protagonistas conocen las consecuencias del hecho delictivo y la reintegración, por el cual las partes vuelven a reinsertarse en sociedad como sujetos capaces de contribuir. No es extraño que en no pocos acuerdos reparatorios las partes desconozcan el propósito perseguido y en muchos casos, solo se persiga un fin de descongestión del sistema, desnaturalizándose el propósito inicial perseguido.

Es cierto que en la ley penal adolescente chilena -Ley No 20.084- se establecen sanciones de corte reparatorio, como son el trabajo en beneficio de la comunidad y la reparación del daño, pero su empleo ha sido más bien escaso. Se arguye la limitada información de que dispone el juzgador como para precisar qué clase de reparación podría satisfacer a la víctima ${ }^{12}$.

En las páginas que siguen expondré el Derecho comparado, en especial la experiencia mexicana y colombiana, dada su proximidad cultural con nuestro país, a fin de precisar cómo se podría introducir en Chile un programa de justicia restaurativa. Pero antes de analizar el Derecho comparado, quisiera ofrecer algunas reflexiones que me permiten afirmar la necesidad de incorporar estos instrumentos en el ordenamiento jurídico penal chileno.

\footnotetext{
12 Díaz (2010), p. 55: "Es probable que una de las razones del escaso número de sanciones de reparación dictadas por los jueces se deba a que la LRPA no contempló plazos ni procedimientos especiales para la realización de procesos restaurativos, de manera que, una vez establecido el veredicto de culpabilidad, no se contempla un plazo o período especial para intentar, por ejemplo, una mediación penal cuyo resultado, de llegar las partes a un acuerdo, pudiera ser considerado por el juez en su sentencia. Tampoco se establecen mecanismos que permitan a los jueces saber cuál es el tipo de reparación que la víctima desea recibir. Sin estos antecedentes, es muy difícil que un juez decida imponer una pena de reparación, especialmente porque cuando la reparación no es monetaria sino que consiste en un trabajo a favor de la víctima, se requiere de su acuerdo y el del joven para poder decretarla. Asimismo, el hecho de que el juez carezca de un informe que le señale si el joven tiene o no capacidad para reparar económicamente a la víctima, puede ser una razón adicional que desincentive a los jueces para decretar esta sanción".
} 


\section{Por qué debieran implementarse mecanismos alternativos para solucionar conflictos penales}

La exigencia de una mayor presencia de la víctima en la solución del conflicto penal es un tema que genera cada vez mayor atención, particularmente, procurar privilegiar dicha solución a través de mecanismos que no deriven en la imposición de una pena ${ }^{13}$. Es decir, que sean los protagonistas del conflicto, el autor y la víctima, quienes determinen formas de responsabilidad y de reparación ${ }^{14}$. Precisamente, es en este contexto donde se presenta el discurso de la llamada justicia restaurativa como mecanismo de solución de conflictos penales, entre ellos la mediación. Como se ha hecho presente, la justicia restaurativa se construye sobre la idea de que el Estado no es "propietario" del conflicto, sino que son los involucrados en él los principales Ilamados a buscar una solución ${ }^{15}$. Asimismo, este modelo se presenta como un proceso deliberativo y participativo, y no adversarial, con el propósito de lograr, entre otros fines, la reparación y la conciliación ${ }^{16}$.

Atendido lo anterior, las diferencias con el sistema tradicional son significativas. Si para la justicia retributiva lo determinante es el quebrantamiento de una norma penal y por ello la imposición de una pena entendida como castigo ${ }^{17}$, en la justicia restaurativa lo esencial no es la sanción penal sino la reintegración de la víctima y del autor a la sociedad a través de la reparación y la asunción de responsabilidad. Todo ello dentro de un proceso de diálogo y de encuentro. Es importante tener presente, que la reparación no solo puede entenderse económica, sino también emocional y simbólica, que la propia víctima vuelva a sentir confianza, reinsertándose en la comunidad -salud mental de la víctima- ${ }^{18}$. Así también, existe especial preocupación en que estas prácticas restaurativas incidan en el autor del hecho, en cuanto son procesos participativos y deliberativos, asumiendo éste sus responsabilidades

13 Aguilera (2012), p. 320.

14 Bazemore (1999), p. 48.

15 Carnevali (2017), p. 123.

${ }^{16}$ DíAz (2010), pp. 2 y 3.

17 Silva (2015), p. 6.

${ }_{18}$ Cuadrado (2015), p. 14: "En otras palabras, el perdón del ofensor no es la única finalidad que persigue la mediación. Entre las opciones disponibles -y más comunes en la práctica-se encuentran -además- la compensación económica, la realización de trabajos de reparación para la víctima o en favor de la comunidad". Acerca del perdón dentro de los procesos restaurativos, Esquinas (2006), p. 97. 
-no a través de la pena-, lo que desde una perspectiva preventiva puede ser particularmente significativo ${ }^{19}$.

No son pocos los antecedentes que nos autorizan para afirmar que el sistema de justicia penal de corte adversarial está en crisis, principalmente de confianza ciudadana ${ }^{20}$. Por de pronto, el exceso de carga laboral no permite atender toda la demanda. Igualmente, la participación de la víctima es apreciada como muy secundaria. Por otro lado, también se presentan cuestionamientos a la pena y su limitada capacidad para cumplir fines resocializadores, más aún si se trata de penas privativas de libertad, sobre todo por su carácter segregador y estigmatizador. ${ }^{21}$

Justamente, la introducción de mecanismos alternativos -como la mediación- para enfrentar el delito pueden mostrarse particularmente eficaces para el logro de la paz social, pues se presta especial cuidado a lo que podríamos afirmar un defecto crónico del sistema tradicional, como es la desatención a la víctima, para quien muchas veces la punición de autor no representa una medida reparadora. Conjuntamente, que el autor se "contacte" con la víctima, que pueda apreciar directamente las consecuencias de su comportamiento, puede fortalecer su proceso de reinserción y el de asumir activamente la responsabilidad para reparar el daño causado ${ }^{22}$. Además, se evita la imposición de una pena privativa de libertad, no exponiendo al autor a un importante factor criminógeno como lo es la convivencia carcelaria. Cabe señalar que estudios en esta materia han puesto en evidencia que la Justicia Restaurativa ha reducido la reincidencia en delitos violentos -en aquellos países que lo admiten para esta clase de crímenes- y en delitos contra la propiedad ${ }^{23}$. Asimismo, la mediación al tener un carácter autocompositivo permite que sean las mismas partes las que alcancen una solución. Es altamente recomendable que éstas se conozcan y logren ellas mismas una respuesta satisfactoria.

La mediación no solo puede cumplir importantes beneficios para los directamente involucrados, sino también genera efectos sociales mayores. En efecto, como se construye dentro de un procedimiento de participación voluntaria y de encuentro, y se inscribe dentro de una cultura de diálogo, se minimiza el uso de la fuerza estatal ${ }^{24}$.

\footnotetext{
19 Al respecto, Roxin (2008), pp. 227-228.

20 Bolívar (2014), p. 15.

21 CID (2009), p. 125.

22 Barona (2011), pp. 263 y ss.; Mera (2009), p. 189.

23 Cuadrado (2015), p. 17.

24 Casanovas et al. (2011), pp. 657 y ss.
} 
De este modo, se otorga un mayor protagonismo a la sociedad civil, pues es ella la llamada a buscar la solución. En un sistema autocompositivo la responsabilidad de alcanzar un acuerdo recae en los propios protagonistas. Incluso, ello permite aumentar la confianza en los sistemas de administración de justicia penal, pues es el propio Estado el que los propicia.

Ciertamente, no se pretende renunciar a un sistema de justicia retributiva ni desconocer el monopolio estatal del ius puniendi, aquello sería una irresponsabilidad, pero sí la búsqueda de otros modelos ${ }^{25}$. Éstos pueden perfectamente insertarse dentro del mismo sistema procesal, articulándose a través de un procedimiento autónomo funcionalmente. Además, estarían sujetos al control de la autoridad, ya sea fiscal o judicial.

En apoyo de lo dicho, debe tenerse presente que los instrumentos propios de la justicia restaurativa permiten materializar principios tan relevantes para el Derecho penal como es el de intervención mínima, pues se recurre a formas de solución de conflictos menos lesivas, pero igualmente eficaces ${ }^{26}$. Esto es, a través de una participación voluntaria y dialogante es posible alcanzar los fines de pacificación social que se esperan del Derecho penal. Está de más decir que no es el único camino y hay mucho que mejorar. No obstante, tal como hoy se aplican las salidas alternativas, así como las penas sustitutivas, no permite aseverar que se logra un efecto de responsabilización, y que muchas veces los autores no son partícipes en el acuerdo ni tampoco se dispone de contenidos restaurativos -encuentros entre autor-víctima-.

Lastimosamente, todavía se ve con cierta desconfianza este tipo de mecanismos, pues impera la idea de que la justicia penal debe ir asociada a la imposición de una pena. Hay, por tanto, una consideración cultural que no es menor, al predominar rasgos autoritarios de nuestra sociedad. En este sentido, incentivar los procesos restaurativos también supone ampliar los canales de participación democrática.

\section{Experiencia comparada. Una especial atención a la legislación mexicana y colombiana}

El primer intento de introducir la práctica restaurativa en el sistema de justicia criminal que ha sido documentado lo encontramos en Canadá en el

${ }^{25}$ González (2015), pp. 710 y ss.; Cuadrado (2015), p. 3.

${ }^{26}$ Sobre el principio de intervención mínima, ver Carnevali (2008), pp. 13 y ss.; Gordillo (2006), p. 94. 
año 1975. Es así que en Ontario se presentó el primer proyecto de reconciliación infractor-víctima ${ }^{27}$.

En Europa el número de países que han introducido mecanismos de Justicia Restaurativa en la esfera de la justicia juvenil ha aumentado continuamente en las últimas décadas. Refrenda la preocupación por el tema, el creciente número de instrumentos internacionales -para adultos como para delincuentes juveniles-, tanto en la Unión Europea, como del Consejo de Europa y las Naciones Unidas en los últimos 15 años. Basta citar los siguientes para apreciar lo afirmado: a) Resolución № 2.002/12 del Consejo Económico y Social de las Naciones Unidas sobre principios básicos sobre utilización de programas de justicia restaurativa en materia penal; b) Recomendación Rec (99) relativa a la mediación en materia penal destaca que la mediación debe estar disponible en todas las etapas del procedimiento penal -4- y que los servicios de mediación deben estar disponibles en general -artículo 3-; c) Recomendación № R. (2006) 2 del Consejo de Europa sobre las Reglas penitenciarias europeas subraya el uso de la restauración y la mediación para resolver conflictos entre y con los reclusos; d) Directiva No 2012/29/UE del Parlamento Europeo y del Consejo de 25 de octubre de 2012 por la que se establecen normas mínimas sobre los derechos, el apoyo y la protección de las víctimas de delitos subraya el beneficio de las intervenciones de justicia reparadora, como la mediación víctima-delincuente o el grupo familiar conferencia a la víctima -art. 46-; e) Recomendación № R. (2003) del Consejo de Europa sobre nuevas formas de tratar con delincuentes juveniles y el papel de la justicia de menores; f) Recomendación No R. (2008) del Consejo de Europa sobre las normas europeas para delincuentes juveniles; g) Recomendación $N^{\circ}$ R. (2003) del Consejo de Europa señala la mejora de las alternativas al enjuiciamiento formal, teniendo en cuenta el principio de proporcionalidad y la libre admisión de responsabilidades -artículo 7-, y h) Directrices del Consejo de Europa (2010) sobre la justicia para la infancia señalan la promoción de alternativas a los procedimientos judiciales, en particular la mediación, el desvío y la resolución alternativa de conflictos $-\mathrm{N}^{\circ} 24-$.

En Austria, la mediación entre víctima y delincuente se ha introducido respecto de los menores en 1988 y para adultos en 2000. Antes de su incorporación al ordenamiento jurídico, la mediación entre víctima y delincuente se contemplaba en un proyecto piloto para jóvenes en $1985^{28}$.

${ }^{27}$ VAn y Strong (2015), pp. 33-38; Beltrán (2009), p. 60.

${ }^{28}$ Dünkel et al. (2015), pp. 19 y ss. 
Cabe destacar que la mediación es predominantemente empleada por los fiscales para suspender el enjuiciamiento. Entre los presupuestos considerados para que un caso pueda desviarse se comprende, entre otros, que los hechos y circunstancias del caso se hayan aclarado adecuadamente, y que la pena máxima prescrita por la ley no exceda los cinco años de prisión. Se exige como un requisito para proceder a la mediación que el imputado esté dispuesto a asumir la responsabilidad del acto cometido.

En general, la evaluación de estos mecanismos tratándose de delincuentes juveniles son positivos, tanto en lo dice relación con las tasas de participación en la mediación como la de los acuerdos. Aproximadamente el $90 \%$ de los delincuentes juveniles e incluso el 96\% de las víctimas aceptaron participar. La gran mayoría de los casos de mediación entre víctima y delincuente $-75 \%$ - dieron como resultado un acuerdo que posteriormente se cumplió.

Bélgica es uno de los pocos países en el mundo donde la justicia restaurativa está disponible para toda clase de delitos, así como para todas las etapas del proceso de justicia penal, tanto para menores como para adultos.

En el caso del Reino Unido, y solo por citar un caso, se puede destacar que respecto a los infractores entre 10 a 17 años que admiten culpabilidad y que son condenados a prisión por primera vez, son remitidos al Ilamado Panel de Delincuentes Juveniles que comprende dos voluntarios de la comunidad local junto con un profesional del Equipo local de Delincuentes Jóvenes. Se requiere que los padres asistan a la reunión del panel si el joven es menor de 16 años, y las víctimas también pueden asistir a la audiencia y participar en las discusiones. En general, dentro del panel se le preguntará al joven sobre lo que sucedió y qué se puede hacer para evitar que vuelva a delinqui ${ }^{29}$.

Resulta fundamental alentar a los delincuentes juveniles que asuman su responsabilidad y reflexionen sobre el daño causado a la víctima o a la comunidad en general. Asimismo, el panel debe determinar un plan que pueda proporcionar la reparación a la víctima o a la comunidad e incluir intervenciones al joven infractor. Lo anterior, incluye tratamientos de drogas y alcohol.

En Alemania los resultados en general han sido positivos. Algunos estudios han precisado que del $80 \%$ al $90 \%$ de los imputados y las víctimas acordaron participar en la mediación. Los acuerdos alcanzaron un promedio de $75 \%$ y en un porcentaje similar los imputados cumplieron los compromisos asumidos $^{30}$.

29 Dünkel et al. (2015), pp. 53 y ss.; MOntesinos (2009), p. 85.

30 Dünkel et al. (2015), pp. 53 y ss.; Barona (2009), pp. 235 y ss. 
Puede afirmarse que Alemania dispone de las mayores regulaciones legales en materia de justicia restaurativa. Es posible hallarla en la Ley de justicia de menores y en el Código de procedimiento penal, donde se establecen normas sobre la mediación y la reparación en todas las etapas del procedimiento penal. Incluso, la Ley de prisiones pone especial acento en cuestiones de restauración.

En los Países Bajos, se pueden encontrar diversas formas de intervenciones restaurativas para jóvenes delincuentes. Al respecto, se pueden mencionar la mediación entre la víctima y el delincuente y las conferencias restaurativas. Así como las órdenes de reparación de la comunidad ${ }^{31}$.

En este breve espacio de tiempo, no es posible exponer todas las experiencias comparadas. Pero sí puede decirse que una tendencia reciente, pero que emerge con intensidad en Europa, son las formas de conferencia. Ya no solo la mediación es el mecanismo más empleado en la justicia restaurativa. El incremento en la implementación de procedimientos de conferencia se debe a las experiencias positivas que han tenido lugar en Nueva Zelanda y Australia desde 1990, los que se han ido extendiendo a Europa y América del Norte ${ }^{32}$.

Las conferencias han dado lugar a altos niveles de satisfacción de los participantes, también se ha apreciado una reducción de los costos para el Estado y menores tasas de reincidencia. Asimismo, las conferencias han Ilegado a ser estimadas como una alternativa viable para abarcar delitos de mayor gravedad que los que cubre tradicionalmente la mediación.

Entrando de lleno en nuestro continente y tal como se destacó supra, México dispone de toda una regulación sobre mecanismos de solución de conflictos en materia penal. En efecto, la ley de 2014 establece todo un procedimiento a seguir, el que se ha implementado en todo el territorio nacional ${ }^{33}$.

Los mecanismos de solución dispuestos son tres, a saber, la mediación, la conciliación y la junta restaurativa. La mediación, conforme al artículo 21, consiste en un mecanismo voluntario por el cual los Intervinientes buscan, construyen y proponen opciones de solución a la controversia, con el fin de alcanzar la solución de ésta. El Facilitador deberá propiciar la comunicación y el entendimiento mutuo entre los Intervinientes. En la conciliación, regulada en el artículo 25, los intervinientes proponen opciones de solución

\footnotetext{
31 DüNKEl et al. (2015), pp. 119 y ss.

32 Maxwell y Morris (1996), pp. 88-110; Hayes et al. (2014), pp. 109-127; Esquinas (2006), p. 89.

33 Entre otros, Geraldes da Gunha (2014), pp. 51 y ss.; Gorjón (2016), pp. 365 y ss.; Zaragoza (2016), pp. 381 y ss.; SÁNCHEZ (2016), pp. 393 y ss.
} 
a la controversia en que se encuentran involucrados. El facilitador no solo debe propiciar la comunicación entre los Intervinientes, sino también sobre la base de criterios objetivos, presentar alternativas de solución diversas. Por último, la junta restaurativa -artículo 27-permite que la víctima u ofendido, el imputado y, en su caso, la comunidad afectada, busquen y propongan opciones de solución a la controversia, con el objeto de lograr un Acuerdo que atienda las necesidades y responsabilidades individuales y colectivas, así como la reintegración de la víctima u ofendido y del imputado a la comunidad, permitiendo la recomposición del tejido social.

La oportunidad para solicitar estos mecanismos será desde el momento en que se inicia el procedimiento penal hasta antes de dictado el auto de apertura a juicio. Así también hasta antes de que se formulen las conclusiones. Todo ello conforme se disponga en la legislación procedimental penal aplicable. La procedencia de estos mecanismos está dispuesta en el artículo 187 del Código nacional de procedimientos penales: a) Delitos que se persiguen por querella, por requisito equivalente de parte ofendida o que admiten el perdón de la víctima o el ofendido; b) Delitos culposos, y c) Delitos patrimoniales cometidos sin violencia sobre las personas.

En términos generales, el artículo 10 de la ley señala que una vez que el Ministerio Público recibe la denuncia o querella deberá orientar al denunciante o querellante sobre los Mecanismos Alternativos de solución de controversias, informándole en qué consisten y su alcance. El Ministerio Público podrá derivar el asunto al órgano adscrito a las procuradurías o fiscalías cuando la víctima u ofendido esté conforme con solicitar el inicio del Mecanismo Alternativo, los Intervinientes se encuentren identificados, y se haya verificado la oportunidad y procedencia de éstos. Ahora bien, si el imputado ha sido vinculado al proceso -formalizado-, es el Juez quien debe derivar el asunto al Órgano respectivo, siempre y cuando el imputado y la víctima u ofendido estén de acuerdo en solicitar el inicio del Mecanismo Alternativo. Los intervinientes podrán determinar el mecanismo alternativo para la solución de su controversia, pudiendo cambiarlo si no se alcanzan acuerdos. Incluso, el propio facilitador puede sugerirlo.

Las sesiones, de acuerdo al artículo 19, deberán realizarse solo con la presencia de los Intervinientes y, en su caso, de auxiliares y expertos, a petición de las partes. Es posible la orientación jurídica y, si cuentan con abogado, éste podrá presenciar las sesiones, pero no podrá intervenir durante su desarrollo. En caso de existir alguna duda de carácter jurídico que no pueda ser resuelta por los auxiliares y expertos invocados por el Facilitador, se podrá solicitar la suspensión de la sesión a fin de consultar con el abogado. Al inicio de la sesión del Mecanismo Alternativo, el Facilitador hará saber a 
los Intervinientes las características del mecanismo, las reglas a observar, así como sus derechos y obligaciones. Todas las sesiones son confidenciales ${ }^{34}$.

En el caso de lograrse un acuerdo -artículo 33-, este puede ser total o parcial. En este segundo caso, se dejará a salvo los derechos de los Intervinientes en relación a lo no resuelto en el Acuerdo, pudiendo dar lugar a las acciones legales que correspondan. El Acuerdo alcanzado deberá ser informado al Ministerio Público y, en su caso, al Juez de control, observándose las reglas para la protección de datos personales. Corresponderá al Ministerio Público o al Juez aprobar el cumplimiento del Acuerdo, determinándose la extinción de la acción penal o el sobreseimiento del asunto -artículo 35-. La resolución emitida por el Juez tendrá efectos de sentencia ejecutoriada. En caso de incumplimiento del Acuerdo, autorizará la continuación del procedimiento penal. Para ello, se dispone de todo un procedimiento para el seguimiento del acuerdo. Al efecto, el Facilitador y los Intervinientes revisarán los motivos por los que se ha producido el incumplimiento y, en su caso, propondrán las modificaciones que deban realizarse y que resulten satisfactorias para todos sin afectar la efectiva reparación del daño -artículo 38-.

Tratándose de Colombia, la regulación de los programas de justicia restaurativa se halla en el Código de Procedimiento Penal ${ }^{35}$. Previamente, antes de enviar el caso a un programa el fiscal o el juez deberá informar a las partes de cuáles son sus derechos, de la naturaleza del acto que se llevará a cabo y de las posibles consecuencias de su decisión. Así también deberá verificar que no se haya coaccionado ni inducido a la víctima ni al infractor para que participen en procesos restaurativos o acepten resultados restaurativos.

Con respecto a la conciliación preprocesal -artículo 522- solo procede respecto de los delitos querellables, esto es, delitos de escasa gravedad que requieren la denuncia de la víctima para iniciar la investigación. Se trata de un requisito de procedibilidad para ejercer la acción penal, ya sea ante el fiscal o en un centro de conciliación o ante un conciliador que sea reconocido como tal. Es así que, en general, se llama a las partes a conciliación, y si ésta se alcanza, se procede al archivo de la causa. En caso contrario, se ejerce la acción penal.

La Ilamada conciliación en el incidente de reparación integral se dispone en el artículo 103. Tiene lugar una vez que la sentencia condenatoria se encuentra firme y ejecutoriada, el juez fallador deberá, previa solicitud, convocar a una audiencia pública con la que dará inicio al incidente de

34 GonzÁlez (2009), p. 32.

35 Al respecto, entre otros, Bernal y Restrepo (s/a), pp. 127 y ss.; Lobo (2010), pp. 79 y ss. 
reparación integral de los daños causados por el delito. Una vez iniciada la audiencia el incidentante formulará su pretensión en contra del o los responsables del delito, exponiendo la forma de reparación integral a la que aspira e indicando las pruebas que hará valer. Si se admite la pretensión el juez la pondrá en conocimiento del condenado, ofreciendo la posibilidad de una conciliación que podría dar término al incidente. En caso contrario, el juez fijará una nueva audiencia para intentar nuevamente la conciliación y, de no lograrse, el sentenciado deberá ofrecer sus propios medios de prueba.

Por último, mediación, tratada en los artículos 523 y siguientes, tiene como propósitos la reparación, restitución o resarcimiento de los perjuicios causados; realización o abstención de determinada conducta; prestación de servicios a la comunidad; o pedimento de disculpas o perdón. Puede recurrirse a ella desde la formulación de la imputación -la formalización-y hasta antes del inicio del juicio oral. Procede respecto de delitos perseguibles de oficio cuyo mínimo de pena no exceda de cinco años de prisión, siempre y cuando el bien jurídico protegido no sobrepase la órbita personal del perjudicado y víctima. En los delitos con pena superior a cinco años, la mediación podrá aplicarse para otorgar algunos beneficios durante el trámite de la actuación, o relacionados con la disminución de la pena.

Las consecuencias de la mediación son importantes, pues excluye el ejercicio de la acción civil derivada del delito y el incidente de reparación integral -artículo 526-. El mediador emitirá un informe acerca de los resultados, enviándolo al fiscal o al juez, según el caso, para que determine sus efectos en la actuación. Los resultados de la mediación serán valorados para el ejercicio de la acción penal; la selección de la coerción personal, y la individualización de la pena al momento de dictarse sentencia.

\section{Propuesta de lege ferenda}

Tal como pone en evidencia la experiencia comparada, es posible pensar en la instauración de un programa de justicia restaurativa ${ }^{36}$. Si bien en Chile se está trabajando actualmente en un modelo para la esfera juvenil, es posible también pensar para aplicarlos respecto de adultos.

Los presupuestos sobre los cuales se asientan estos mecanismos son plenamente justificables tratándose de los adultos, y que se expresan en la Resolución No 2002/12 del Consejo Económico y Social de las Naciones

${ }^{36}$ Cuadrado (2015), pp. 8 y ss., quien distingue diversas formas de mediación que pueden ser introducidas en el ordenamiento jurídico. 
Unidas $^{37}$. Nociones como reparación, responsabilización -se parte de que existen antecedentes para inculpar-y reintegración, que pueden ser valorados desde una perspectiva preventiva general y especial, se encuentran recogidas en los programas restaurativos.

Como ya se hizo presente en otro trabajo ${ }^{38}$, dado que los propósitos que persiguen la justicia retributiva y la justicia restaurativa son diversos, no es posible imponer a esta última las mismas exigencias garantísticas de aquélla. En efecto, no puede dejarse de tener presente que la alta exigencia de la justicia retributiva se justifica por cuanto se puede llegar a privar de la libertad al imputado de un delito y condenarlo por largo tiempo. De allí pues el esfuerzo por introducir un alto rigor garantístico. Cuestión que debe observarse de manera distinta tratándose de la justicia restaurativa. Y es que no se requiere tal exigencia, pues lo que propone aquí es, esencialmente, la solución del conflicto y la reparación, no la imposición de un castigo penal. No se discute si se está frente a un hecho que el Estado debe probar que se trata de un delito, de manera que al desvirtuarse la presunción de inocencia autorizaría al juzgador para condenar ${ }^{39}$. En la esfera de la justicia restaurativa más que buscar la verdad de los hechos lo fundamental es que a través del encuentro entre el autor y la víctima -en un plano de igualdad-se alcance la reparación de esta última, que permita la reinserción y la inclusión de ambos en los términos expuestos precedentemente.

Por cierto, lo expuesto no supone que se dejen de considerar estándares mínimos, como son los de igualdad, información previa y participación voluntaria. Asimismo, la participación del imputado no puede significar reconocimiento de culpabilidad y no es posible emplear los antecedentes, en caso de que fracase la mediación, en el futuro procedimiento y eventual juicio ${ }^{40}$.

Considerando lo anterior, es posible construir un modelo que puede instaurarse en nuestro sistema para atender ciertos casos, lo que no solo permitiría descongestionarlo -si bien no es el fin principal no es posible eludir que es uno de los objetivos-, sino que también brindaría un mensaje a la sociedad, de que existe una preocupación particular por la víctima, al

\footnotetext{
37 Ver Consejo Económico y Social de las Naciones Unidas (2002). También véase Consejo de Europa sobre Mediación en Justicia Penal (1999).

${ }^{38}$ Carnevali (2017), pp. 122 y ss.

${ }^{39}$ Gordillo (2006), p. 116.

${ }^{40}$ Cuadrado (2015), p. 19.
} 
tener esta la oportunidad de poder participar directamente en la solución del conflicto $^{41}$.

Respecto de los delitos que pueden comprenderse dentro del modelo en comento, me parece que solo pueden seleccionarse para ser mediados -entendiendo que la mediación es generalmente el mecanismo más utilizado- aquellos sobre los cuales no se ejerce violencia sobre las personas, como sucede en los delitos contra la vida, lesiones graves, algunas hipótesis de robos y de delitos sexuales ${ }^{42}$. Reconozco que es un tema discutible, pues también puede pensarse que debe quedar abierta la posibilidad de que sean las propias partes las que decidan si quieren someterse o no a mediación. En rigor, los mecanismos alternativos lo que pretenden es abordar el conflicto que subyace en la comisión de un delito y ver cómo subsanar el daño causado a las víctimas y reintegrarlas a la sociedad, al igual que al autor. Apreciado en estos términos, no debería restringirse el elenco de delitos. Empero, dadas las particularidades de nuestra sociedad, tan proclive-como se subrayó supra-a estimar que solo la pena puede resolver un conflicto penal, me lleva a pensar que debe obrarse con mesura, restringiendo el catálogo solo a aquellos delitos que generan menor consternación social.

En lo que respecta a la oportunidad procesal para poder recurrir a estos instrumentos, debe abarcar desde el inicio de la investigación hasta la dictación de la sentencia. Incluso, soy del parecer de ampliarla al momento de su ejecución ${ }^{43}$.

Para ser más claros, es posible distinguir tres momentos:

a) Ingreso hasta antes de la audiencia de formalización. Etapa no judicializada.

b) Desde la formalización hasta la sentencia. Etapa judicializada.

c) Ejecución de la sentencia hasta su cumplimiento total. Etapa condenatoria.

Tratándose de la primera etapa, esto es, la prejudicializada, es posible comprenderlas dentro de los términos facultativos del fiscal. Ciertamente, es más rápida, pues no se requiere de una audiencia ante un juez, por lo que puede aplicarse, luego de que tenga lugar el proceso restaurativo, el principio de oportunidad ${ }^{44}$.

\footnotetext{
41 GonZÁlez (2009), p. 25.

42 González (2009), p. 40.

${ }^{43}$ González (2009), pp. 43 y ss.

${ }^{44}$ Francés (2012), pp. 1 y ss.; Cuadrado (2015), p. 9; Gordillo (2006), pp. 97 y ss.; Casanovas et al. (2011), p. 703.
} 
Lo anterior permite enfrentar un problema de creciente preocupación por parte de la ciudadanía, como es la atención que se le presta a la víctima y el rol más activo que ésta puede tener, más allá de lo que propone el artículo 170 del Código procesal penal. En efecto, conforme al precepto en comento la víctima puede, dentro de los diez días de tomada la decisión por parte del fiscal, solicitar que se deje sin efecto si manifestare de cualquier modo su interés en el inicio o en la continuación de la persecución penal.

Se puede disponer, tal como sucede en Colombia, que, si la víctima manifiesta su propósito de continuar, debe someterse a un proceso de mediación. Dado que queda entregado a la decisión del juez, éste puede determinar que para resolver las partes deberán sujetarse a una mediación. Si se logra un acuerdo, se aplica el principio de oportunidad. En caso contrario, el juez resolverá si se continúa o no con la persecución penal. Lo anterior entrega un espacio para que la víctima y el autor puedan solucionar su conflicto y lograr la reparación y satisfacción de quien es víctima.

En lo que dice relación a la segunda etapa puede afirmarse que es la más frecuente en la práctica, y que la aplicación de procesos restaurativos se podría apreciar con la aplicación de las salidas alternativas, a saber, la suspensión condicional del procedimiento y los acuerdos reparatorios ${ }^{45}$. No obstante, como se afirmó precedentemente, no son propiamente programas de justicia restaurativa, por lo que se desaprovechan estas instancias para su aplicación. Me parece que respecto a los acuerdos reparatorios es plenamente aplicable lo que se explicó de la legislación mexicana. En efecto, a fin de darle un efectivo carácter restaurativo a los acuerdos, es imprescindible que los intervinientes se sometan a un proceso de mediación. Luego, de lograrse un acuerdo, éste pueda refrendarse ante el juez. Asimismo, debe regularse el seguimiento del mismo, esto es, verificar si se está o no llevando a cabo el acuerdo alcanzado. Para ello deberá de disponerse de personal que permita verificarlo. Al respecto, se puede seguir el modelo adoptado por la ley mexicana citada precedentemente.

Por último, en lo que respecta a la tercera etapa, me parece que la ley colombiana nos entrega una interesante regulación. Se puede establecer que durante el debate al que alude el artículo 342 del Código Procesal Penal y solo respecto de los delitos en los que procede el modelo, que el juez proponga a las partes someterse a mediación. En caso de alcanzarse un acuerdo y la víctima sea reparada, pueda suponer ya sea, una suspensión de la condena o una disminución de la pena. Así también, puede contemplarse la aplicación

${ }^{45}$ González y Fuentealba (2013), pp. 175 y ss. 
de alguna pena sustitutiva, especialmente útil sería el trabajo en beneficio de la comunidad. Lo anterior, es posible incluso durante el período de ejecución de la sentencia ${ }^{46}$.

\section{Algunas consideraciones finales}

Si bien existen en Chile experiencias piloto donde se Ilevan a cabo procesos de mediación a través de la Corporación de Asistencia Judicial, no se comprenden dentro de una política institucionalizada ${ }^{47}$. Sí es necesario destacar la existencia de proyectos respecto de la delincuencia juvenil, donde se incorporan procedimientos de mediación. Es de esperar que puedan materializarse a fin de que en futuro próximo se comprendan dentro del sistema de adultos.

Ciertamente, hay mucho por avanzar. Aún impera cierto escepticismo respecto de este tipo de modelos, pues estamos acostumbrados a que los conflictos penales se resuelvan sobre la base del antagonismo y que sea un tercero el que lo haga. En este sentido, se presentan, como ya se expuso, consideraciones culturales y rasgos autoritarios no menores en nuestra sociedad $^{48}$. Por ello resulta tan importante exponer estos modelos y dar cuenta que existen otros mecanismos para resolver conflictos, construidos sobre la base del diálogo, el encuentro y la reparación.

Se trata de procedimientos que no pueden concebirse como alternativos o separados de la justicia penal tradicional, sino que complementarios e incorporados a ésta ${ }^{49}$. De este modo, pueden satisfacer de mejor forma los fines tanto de prevención general como especial que se esperan de todo sistema que procura la solución de conflictos penales ${ }^{50}$.

\footnotetext{
${ }^{46}$ Ver los arts. 80 y ss. del Código penal español, en particular el art. 84. Esta disposición señala que el juez o tribunal también podrá condicionar la suspensión de la ejecución de la pena al cumplimiento de alguna prestación, siendo una de ellas el cumplir el acuerdo alcanzado por las partes en virtud de mediación.

47 Sobre la materia, Navarro y Díaz (2015), pp. 5 y ss.

${ }^{48}$ Díaz (2010), pp. 56-57.

${ }^{49}$ Como señala Cuadrado (2015), p. 9: "la mediación puede ser introducida como método relativamente independiente del proceso judicial, pero integrado en el sistema de justicia penal ya existente; es decir, que en este caso no se trata de innovar -en el sentido de crear un nuevo sistema de justicia independiente y paralelo al convencional-, sino de implementarlo, combinando sus valores y prácticas, con las existentes en el propio sistema del cual surgen".

${ }^{50}$ Esquinas (2006), p. 71.
} 


\section{BiBLIOGRAFÍA CITADA}

Aguilera Morales, Encarnación (2012): "La mediación penal: ¿quimera o realidad?", en: Garciandía González, Pedro y Soleto Muñoz, Helena (coordinadores), Sobre la mediación penal (Posibilidades y límites en un entorno de reforma del proceso penal español) (Pamplona, Aranzadi), pp. 315-343.

Barona VILAR, Silvia (2011): Mediación penal, fundamento, fines y régimen jurídico (Valencia, Editorial Tirant lo Blanch).

BARONA VILAR, Silvia (2009): "Situación de la justicia restaurativa y la mediación penal en Alemania", en: Barona, Silvia (directora), La mediación penal para adultos. Una realidad en los ordenamientos jurídicos (Valencia, Tirant lo Blanch), pp. 235-287.

Bazemore, Gordon y Walgrave, Lode (1999): Restorative Juvenile Justice: Repairing the Harm of Youth Crime (Monsey, Criminal Justice Press).

Beltrán Montoliu, Ana (2009): "Modelo de mediación en los Estados Unidos de América", en: Barona, Silvia (director), La mediación penal para adultos. Una realidad en los ordenamientos jurídicos (Valencia, Tirant lo Blanch), pp. 53-82.

Bernal Mesa, Bibiana y Restrepo Serrano, Federico (2015): “¿Por qué en Colombia se habla de conciliación y no de mediación?", en: Vargas, Juan Enrique y Gorjón, Francisco (coordinadores), Arbitraje y mediación en las Américas (Santiago, Centro de Estudio de Justicia de las Américas, Universidad autónoma de Nuevo León), pp. 127-141.

Blanco, Rafael; Díaz, Alejandra; Heskia, Joanna y Rojas, Hugo (2004): "Justicia restaurativa: Marco Teórico, experiencias comparadas y propuestas de política pública", en: Colección de investigaciones jurídicas (№ 6), pp. 3-91.

Bolívar Fernández, Daniela (2014) "La mediación víctima-ofensor como alternativa al sistema penal: la perspectiva de las víctimas", en: Sistema penal \& Violencia (Vol. 6, № 1), pp. 13-30.

Camargo, Humberto; Morales, Lemmy y Osuna, Wilfrido (2010): "La implementación del principio de oportunidad en la legislación penal colombiana", en: Justicia Juris (Vol. 6, № 13), pp. 79-92.

Carnevalı, Raúl (2017): "La justicia restaurativa como mecanismo de solución de conflictos. Su examen desde el derecho penal", en: Justicia Juris (Vol. 13, $\left.\mathrm{N}^{\mathrm{0}} 1\right)$, pp. 122-132.

Carnevali, Raúl (2008): "Derecho Penal como ultima ratio. Hacia una política criminal racional", en: lus et Praxis (Año 14, No 1), pp. 13-48. 
Casanovas, Pompeu et al. (2011): Libro Blanco de la Mediación en Cataluña (Barcelona, Departament de Justícia, Generalitat de Catalunya).

Cid Moliné, José (2009) "Medios alternativos de solución de conflictos y derecho penal", en: Revista de estudios de la justicia ( $N^{\circ} 11$ ), pp. 111-130.

Comisión de Constitución, Legislación, Justicia y Reglamento, Senado (2017): "Informe de la Comisión de Constitución, Legislación, Justicia y Reglamento recaído en el proyecto de ley, en primer trámite constitucional, que crea el Servicio Nacional de Reinserción Social Juvenil e introduce modificaciones a la Ley $N^{0} 20.084$, sobre responsabilidad penal de adolescentes, y a otras normas que indica, Boletín No 11.174-07". Disponible en: https:// www.camara.cl/pley/pdfpley.aspx?prmID=19862\&prmTIPO=INFORMEP LEY [visitado el 11.12.17].

Consejo Económico y Social de las Naciones Unidas (2002): "Principios básicos para la aplicación de programas de justicia restaurativa en materia penal". Disponible en: http://www.ararteko.net/RecursosWeb/ DOCUMENTOS/1/0_1080_1.pdf [visitado el 11.12.17].

Cuadrado Salinas, Carmen (2015): "La mediación: ¿una alternativa real al proceso penal?", en: Revista Electrónica de Ciencia Penal y Criminología (No 17-01), pp. 1-25.

DíAz Gude, Alejandra (2010): "La experiencia de la mediación Penal en Chile", en: Revista Política Criminal (Vol. 5, № 9), pp. 1-67.

Dünkel, Frieder; Horsfield, Philip y Parosanu, Andrea (2015): "Research and Selection of the Most Effective Juvenile Restorative Justice Practices in Europe: Snapshots from 28 EU Member States, International Juvenile Justice Observatory". Disponible en: https://www.oijj.org/en/docs/publications/ research-and-selection-of-the-most-effective-juvenile-restorative-justicepractice [visitado el 11.12.17].

Esquinas VAlverde, Patricia (2006): "La mediación entre la víctima y el agresor como forma alternativa de resolución del conflicto en el sistema judicial penal de adultos: ¿una posibilidad también viable en España?", en: Revista Penal (No 18), pp. 55-101.

Francés Lecumberri, Paz (2012): "El principio de oportunidad y la justicia restaurativa. Mediación, conciliación y reparación en la ley orgánica de responsabilidad penal del menor", en: InDret ( $\left.\mathrm{N}^{\circ} 4\right)$, pp. 1-42.

Geraldes da Gunha Lopes, Teresa María (2014): "Justicia restaurativa y mediación comunitaria. Emergencia de un nuevo paradigma de impartición de justicia", en: Letras jurídicas ( $\left.N^{0} 29\right)$, pp. 51-68. 
González Cano, María Isabel (2015): "La mediación en el proceso penal. Perspectiva de futuro de la justicia restaurativa en el Borrador de Código procesal penal de 2012", en: Moreno Catena, Víctor (director), Reflexiones sobre el nuevo proceso penal (Valencia, Tirant lo Blanch), pp. 687-713.

GonzÁlez Cano, María Isabel (2009): "La mediación penal en España", en: Barona, Silvia (directora), La mediación penal para adultos. Una realidad en los ordenamientos jurídicos (Valencia, Tirant lo Blanch), pp. 19-52.

GonzÁlez Ramírez, Isabel (2014): “¿Es necesario incorporar formalmente mecanismos propios de la justicia restaurativa en el sistema penal chileno?", en: González, Isabel (directora), Justicia Restaurativa: Herramientas para el cambio desde la gestión del conflicto (Santiago, Anuario del centro de mediación, negociación y arbitraje de la Universidad Central de Chile), pp. 23-101.

González Ramírez, Isabel Ximena y Fuentealba Martínez, María Soledad (2013): "Mediación penal como mecanismo de justicia restaurativa en Chile", en: Revista Chilena de Derecho y Ciencia Política (Vol. 4, № 3), pp. 175-210. Gordillo Santana, Luis (2006): "Los principios constitucionales y las garantías penales en el marco del proceso de mediación penal", en: Revista electrónica del Departamento de Derecho de la Universidad de La Rioja ( $\left.N^{\circ} 4\right)$, pp. 87-124.

Gorjón Gómez, Gabriel (2016): “El acuerdo del proceso de justicia restaurativa (acuerdo restaurativo)", en: Sánchez, Arnulfo y López, Patricia (coordinadores), Tipología contractual de los mecanismos alternativos de solución de conflictos (Pamplona, Editorial Aranzadi), pp. 365-392.

Hayes, Hannessey; McGee, Tara Renae; Punter, Helen y Cerruto, Michael John (2014): "Agreements in Restorative Justice Conferences. Exploring the Implications of Agreements for Post-Conference Offending Behaviour", en: British Journal of Criminology ( $N^{\circ}$ 54), pp. 109-127.

LOBo Romero, Catalina (2016): "La mediación penal como programa de justicia restaurativa en el procedimiento penal colombiano", en: Cuadernos de Derecho Penal (julio-diciembre), pp. 51-87.

Maxwell, Gabriel y Morris, Allison (1996): "Research on Family Group Conferences with Young Offenders in New Zealand", en: Hudson, J., Morris, A., Maxwell, G. y Gallaway, B. (editores), Family Group Conferences. Perspectives on Policy and Practice (Monsey NY, The federation Press, Criminal Justice Press), pp. 88-110. 
Mera González-Ballesteros, Alejandra (2009): "Justicia Restaurativa y Proceso Penal Garantías Procesales: Límites y Posibilidades", en: Ius et Praxis (Vol. 15, No 2), pp. 165-195.

Montesinos García, Ana (2009): "La mediación penal en Inglaterra y Gales", en: Barona, Silvia (directora), La mediación penal para adultos. Una realidad en los ordenamientos jurídicos (Valencia, Tirant lo Blanch), pp. 85-123.

NAVARRO, Iván y Díaz, Alejandra (2015): Informe sobre Experiencias Nacionales de Mediación Penal y Justicia Restaurativa en Chile (Santiago, Ministerio de Justicia de Chile).

Roxin, Claus (2008): "La reparación en el sistema de los fines de la pena", en: Roxin, Claus, Fundamentos político-criminales del Derecho Penal (Buenos Aires, Hammurabi), pp. 205-237.

Sánchez García, Arnulfo (2016): "El acceso a los MASC en el contexto de los derechos humanos: una visión desde el principio de legalidad en México", en: Vásquez, María Fernanda, Carnevali, Raúl y Palomo, Diego (coordinadores), Mecanismos alternativos solución de conflictos. Un estudio multidisciplinar (Santiago, Editorial Jurídica de Santiago), pp. 393-406.

Silva SÁnchez, Jesús María (2015): En búsqueda del Derecho Penal (Buenos Aires, Editorial B de F).

SubdireCCIÓN de ArChivo y Documentación (2008): "Reforma constitucional en materia de justicia penal y seguridad pública (proceso legislativo)", en: Secretaría de servicios parlamentarios centro de documentación, información y análisis dirección de bibliotecas y de los sistemas de información. Disponible en: http://www.diputados.gob.mx/sedia/biblio/archivo/sad-0708.pdf [visitado el 13.12.17].

Van Ness, Daniel y Strong, Karen (2015): Restoring Justice. An Introduction to Restorative Justice (Ohio, Anderson Publishing).

Zaragoza Huerta, José (2016): "La justicia restaurativa durante la ejecución de la pena privativa de libertad en México", en: Vásquez, María Fernanda, Carnevali, Raúl y Palomo, Diego (coordinadores), Mecanismos alternativos solución de conflictos. Un estudio multidisciplinar (Santiago, Editorial Jurídica de Santiago), pp. 381-392. 
